\title{
The effects of triazole Compounds on leaf Morphological and Anatomical Characteristics of Radish (Raphanus sativus L.)
}

\author{
R. Sridharan*, S. Raja \\ Department of Botany, Annamalai University, Annamalai Nagar - 608002 Tamil Nadu, India \\ *E-mail address: sridharanbot@gmail.com
}

\begin{abstract}
In the present investigation was carried out to find out the impact of Triadimefon(TDM) and hexaconazole (HEX) triazole fungicides on the leaf anatomy of Radish (Raphanus sativus L.) The plant was treated with one litre of aqueous solution containing $20 \mathrm{mg}^{-1}$ triadimefon (TDM) and $20 \mathrm{mg}^{-1}$ hexaconazole (HEX) on 23,35 and 53, days after sowing (DAS) by soil drenching. The plants were harvested on 30,45 and 60 days after sowing. The total leaf area, thickness of leaf, number of stomata in lower epidermis, stomatal pore length and width were observed in both control and treatments. Leaves treated with TDM and HEX showed several variations in the anatomical characteristics when compared to the leaves of the untreated control plant of Raphanus sativus.
\end{abstract}

Keywords: Raphanus sativus; Triadimefon; Hexaconazole; leaf anatomy; stomata

\section{INTRODUCTION}

Triazole compounds are systemic fungicides, which have plant growth regulating properties (Fletcher and Hofstra 1990). The impact of triazole plant growth regulators on hormonal changes (Ye et al. 1995; Fletcher et al. 2000), The plant growth regulating properties of triazoles are mediated by their inference with isoprenoid pathway and shift in the balance of plant hormones (Fletcher et al. 2000). Triazole compounds are mostly used as systemic fungicides to control fungal diseases in plants and animals. They inhibit gibberellins biosynthesis and modify the sterol metabolism in the host and parasite organism. Triazole compounds like triadimefon (TDM), hexaconazole (HEX), paclobutrazol (PBZ), uniconazole (UCZ) etc., have plant growth regulating properties and effectively retard the shoot growth in monocotyledons and dicotyledons (Jaleel et al.2007a-b). Triazole acts as plant growth regulator and also influences the hormonal balance, photosynthetic rate, enzyme activities, lipid peroxidation and yield components in various crop plants (Jaleel et al. 2008a-b). Previous works proved the ability of triazole compounds such as triadimefon (TDM) in enhancing the antioxidant potential in plant like Catharanthus roseus (Jaleel et al. 2006). Triazole compounds increased the translocation of photosynthates from shoot to root and have altered the mineral uptake and plant nutrition (Gomathinayagam et al. 2007). Triazole inhibits the shoot growth and increases the root growth. Triazoles affect the activities of several enzymes, especially those related todetoxification of active oxygen species and antioxidant metabolism (Lakshmanan et al.2007).The information available so far about the effect of triazole on leaf anatomy in plants is less. Hence it is aimed to understand the effect of triazole 
compounds such as triadimefon (TDM), hexaconazole (HEX) in (Raphanus sativus L.).The objectives of the present investigation were to study the impact of TDM and HEX on The total leaf area, thickness of leaf, number of stomata in lower epidermis, stomatal pore length and width were observed in Raphanus sativus L. plants.

\section{MATERIALS AND METHODS}

\subsection{Seed collection}

The seeds of Raphanus sativus L. var. Pusa Chetki were obtained from Mahycohybrid seeds Co. Ltd, Maharastra. The field part work was carried out in Botanical Garden and analyses were done in Stress Physiology Lab, Department of Botany, Annamalai University, Tamil Nadu.

\subsection{Treatments and samplings}

The present investigation, field experiment was completely in Randomized block design (CRBD) 3 replicates in the Radish during 2012- 2013. Each plant was treated with $20 \mathrm{mg}^{-1}$ TDM and $20 \mathrm{mg}^{-1}$ HEX on 23, 38 and 53 days after sowing (DAS). The treatments were given by soil drenching. The fully expended mature leaves of plants which emerged after the treatments were collected randomly on 30,45 and 60 DAS from each concentration and control plants.

\subsection{Preparation of Free Hand Sections}

The leaves were washed thoroughly with water and fixed them in formalin: acetic acid: ethyl alcohol $(5: 5: 90 \mathrm{v} / \mathrm{v} / \mathrm{v})$. Thin transverse-sections were taken, stained and observed under calibrated light microscope and the thickness of leaf was measured by precalibrated ocular micrometer. Epidermal peels were taken out from the basal, middle and apical regions by adopting direct peel method. The epidermal peels were stained with $1 \%$ Delafield's haematoxylin and mounted in 50\% glycerin (Dwivedi and Singh 1990). The observations were taken on 30, 45 and 60 DAS in 3 replicate peels in each treatments. The leaf thickness expressed in micrometers and number of stomata in lower epidermal cells per unit area were calculated by using the generally followed formula of Metcalfe and Chalk (1979). The length and width of stomatal pores were measured randomly in each treatment on the lower surface of leaf. The total leaf area of the plants was measured using LICOR leaf electric area meter and expressed in $\mathrm{cm}$ per plant.

\subsection{Statistical Analysis}

The experiment was conducted by completely randomized block design (CRBD). Statistical analysis were performed using the one -way (ANOVA) analysis of variance followed by the duncans multiple range test (DMRT). The values mean \pm SD for 3 samples in each group $\mathrm{P}<0.05$ were considered as significant. 


\section{RESULTS AND DISCUSSION}

The total leaf area of the plant decreased with the age in all the treatments. The more decrease was prominent in HEX treated plants and it was 103.41 per cent on 60 DAP when compared to TDM treated plants. TDM and HEX treatments were reducing total leaf area when compared to control in Raphanus sativus plants. Triadimefon reduced the leaf area in wheat (Gao etal.,1988).triazoles increased the leaf thickness by inducing additional layers of palisade mesophyll cells which has a smaller diameter as in soybean, wheat and chrysanthemum (burrows etal.,1992). Fig 1: Effect of Triadimefon and Hexaconazole on plant total leaf area of Raphanus sativus on different growth stages. Thickness of leaves treated with triazoles was increased to a level higher than that of control leaves in radish (Raphanus sativus ) plants. Among the triazole treatments there is no significant variation in thickness of leaf (Table 1). TDM treatments increased the thickness of leaf in plants (Asami et al. 2000).Several variations like stomatal pore length, width and unequal accessory cells were observed in treated leaves. In the case of untreated leaves all stomata are open and have large stomatal pore length but width of stomata gradually decreased in the leaves of treated plants (Table 1). Triazole treatments caused the closure of stomata in bean (Fletcher and Hofstra 1988). Thiapenthenol reduced stomatal opening and reduced water consumption in mesophyll, a transient raise in the ABA content in bean (Asare-Boamah et al. 1986). This increased $\mathrm{ABA}$ content might have induced the stomatal closure as observed in uniconazole treated Phaseolus vulgaris (Mackay et al. 1990). From the above observations it is clear that the triazole compounds affected stomatal pore length and width, stomatal pore size, thickness of leaf and the number of stomata, This is in accordance with the previous reports of Bora et al. (2002) and Gupta et al. (2004). It is previously reported that the application of PBZ can increase the xylem water potentials (Thakur et al. 1998) and can increase the cytokinins under drought conditions (Zhu et al. 2004). The judicious application of triazole like TDM and HEX may prove to be a useful tool for decreasing transpiration and inturn inducing drought avoidance mechanisms. It can be concluded that triazole such as TDM and HEX may be useful to trigger drought avoidance mechanisms in plants like radish (Raphanus sativus ).

\section{Results}

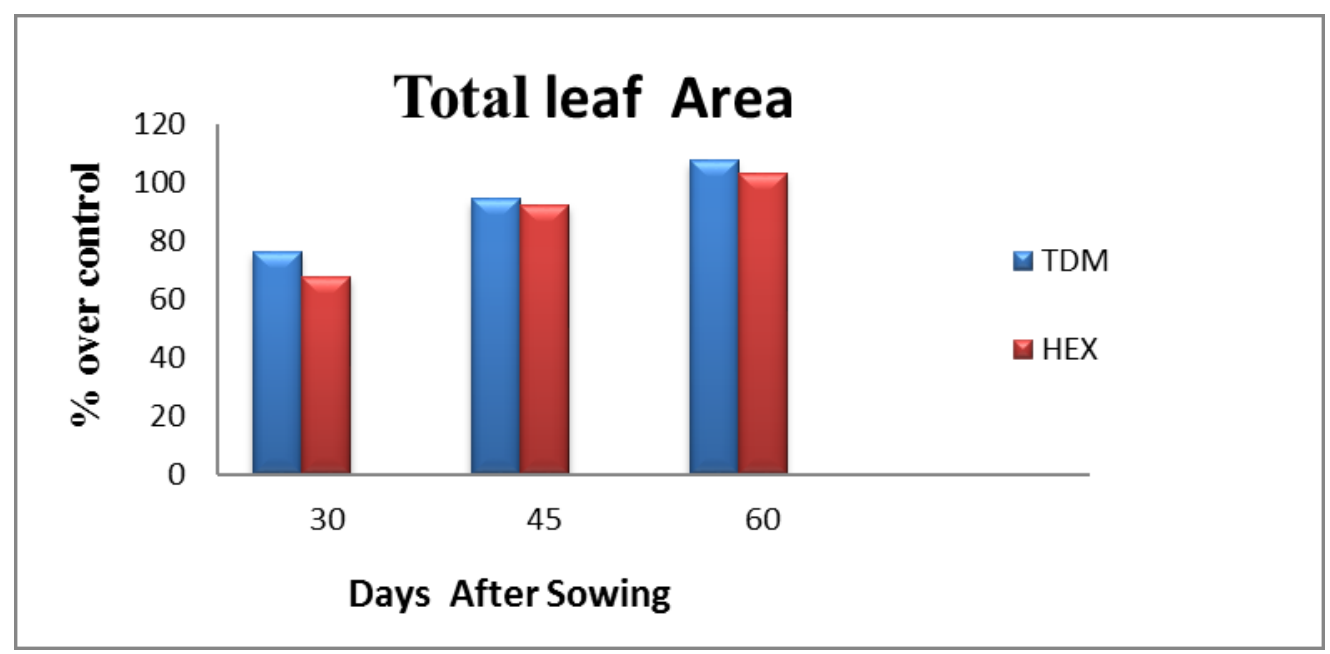

Figure 1. Triadimefon and Hexaconazole induced changes in the Total leaf area of radish $\left(\mathrm{Cm}^{2}\right.$ plant $\left.^{-1}\right)$. 
Table 1. Triadimefon and Hexaconazole induced variation in ,stomata, stomatal pore length and width (values are mean $\pm \mathrm{SD}$ of 3 replicates expressed values in $\mu$ meter).

\begin{tabular}{|c|c|c|c|c|}
\hline \multirow{2}{*}{$\begin{array}{c}\text { Growth } \\
\text { Parameters }\end{array}$} & $\begin{array}{c}\text { Growth } \\
\text { Stages } \\
\text { (DAS) }\end{array}$ & Control & $\begin{array}{c}\text { Triadimefon } \\
(\mathrm{TDM})\end{array}$ & $\begin{array}{c}\text { Hexaconazole } \\
\text { (HEX) } \\
20 \mathrm{mgL}^{-1}\end{array}$ \\
\hline $\begin{array}{c}\text { stomata in } \\
\text { lower } \\
\text { epidermis }\end{array}$ & 30 & $21.50 \pm 0.50$ & $27.75 \pm 0.27$ & $22.59 \pm 0.84$ \\
\cline { 2 - 5 } & 45 & $22.70 \pm 0.53$ & $29.51 \pm 0.46$ & $25.39 \pm 0.63$ \\
\cline { 2 - 5 } & 60 & $23.72 \pm 0.61$ & $30.62 \pm 0.57$ & $27.65 \pm 0.64$ \\
\hline $\begin{array}{c}\text { Stomatal } \\
\text { pore length }\end{array}$ & 30 & $14.10 \pm 1.58$ & $13.93 \pm 0.75$ & $13.53 \pm 0.61$ \\
\cline { 2 - 5 } & 45 & $18.49 \pm 0.18$ & $15.30 \pm 0.28$ & $16.29 \pm 0.34$ \\
\cline { 2 - 5 } & 60 & $20.34 \pm 0.42$ & $18.19 \pm 0.82$ & $17.65 \pm 1.28$ \\
\hline $\begin{array}{c}\text { Stomatal } \\
\text { pore width }\end{array}$ & 30 & $5.66 \pm 0.41$ & $5.16 \pm 0.46$ & $4.94 \pm 0.40$ \\
\cline { 2 - 5 } & 45 & $6.22 \pm 0.38$ & $5.61 \pm 0.18$ & $4.94 \pm 0.16$ \\
\cline { 2 - 5 } & 60 & $6.96 \pm 0.20$ & $6.25 \pm 0.33$ & $6.03 \pm 0.15$ \\
\hline \multirow{2}{*}{} & 45 & & & \\
\hline
\end{tabular}

\section{CONCLUSION}

The judicious application of triazole like TDM and HEX may prove to be a useful tool for decreasing transpiration and inturn inducing drought avoidance mechanisms. It can be concluded that triazole such as TDM and HEX may be useful to trigger drought avoidance mechanisms in plants like Raphanus sativus L.

\section{References}

[1] Bora KK, Mathur SR, Ganesh R, Bohra SP (2002) Effect of paclobutrazol on water loss of excised groundnut seeds. Bioregulants and Applied Plant Biotechnology. Pointer Publishers, India, pp. 58-64.

[2] C.A. Jaleel, P. Manivannan, G. M. A.Lakshmanan, R. Panneerselvam, Triadimefon induced changes in the antioxidant metabolism and ajmalicine production in Catharanthus roseus (L.) G. Don. Plant Sci.171 (2006) 271-276.

[3] Fletcher, R.A., Hofstra, G., 1990: Improvement of uniconazole induced protection in wheat seedlings. J Plant Growth Regulation 9,207-212. 
[4] Fletcher, R.A., Gilley, A., Sankhla, N., Davis, T.M., 2000: Triazoles as plant Growth regulators and stress protectants. Hort. Rev 24, 56-138.

[5] Gao J, Hofstra G, Fletcher RA (1988) Anatomical changes induced by triazoles in wheat seedlings. Can J Bot 66:1178-1185.

[6] Gomathinayagam M., Jaleel C.A., Lakshmanan G.M.A., Panneerselvam R. (2007): Changes in carbohydrate metabolism by triazole growth regulators in cassava (Manihot esculenta Crantz); effects on tuber production and quality. Comptes Rendus Biologies, 330: 644-655.

[7] Gupta SK, Raghava RP, Raghava N (2004) Stomatal studies of cowpea (Vigna unguiculata (L.) Walp.) cultivars in relation to bromiconazole. J Ind Bot Soc 83:116119.

[8] Jaleel C.A., Gopi R., Manivannan P., Kishorekumar A., Gomathinayagam M., Panneerselvam R. (2007a): Changes in biochemical constituents and induction of early sprouting by triadimefon treatment in white yam (Dioscorea rotundata Poir.) tubers during storage. Journal of Zhejiang University Science: B, 8: 283-288.

[9] Jaleel C.A., Manivannan P., Gomathinayagam M., Sridharan R., Panneerselvam R. (2007b): Responses of antioxidant potentials in Dioscorea rotundata Poir. following paclobutrazol drenching. Comptes Rendus Biologies, 330: 798-805.

[10] Jaleel C.A., Gopi R., Manivannan P., Gomathinayagam M., Murali P.V., Panneerselvam R. (2008a): Soil applied propiconazole alleviates the impact of salinity on Catharanthus roseus by improving antioxidant status. Pesticide Biochemistry and Physiology, 90: 135-139.

[11] Jaleel C.A., Lakshmanan G.M.A., Gomathinayagam M., Panneerselvam R. (2008b): Triadimefon induced salt stress tolerance in Withania somnifera and its relationship toantioxidant defense system. South African Journal of Botany, 74: 126-132.

[12] Lakshmanan G.M.A., Jaleel C.A., Gomathinayagam M., Panneerselvam R. (2007): Changes in antioxidant potential and sink organ dry matter with pigment accumulation induced by hexaconazole in Plectranthus forskholii Briq. Comptes Rendus Biologies, 330: 814-820.

[13] Metcalfe CR, Chalk L (1979) Anatomy of the dicotyledons, 2nd eds., vol. 1,Clerendon Press, Oxford.

[14] Thakur A, Thakur PS, Singh RP (1998) Influence of paclobutrazol and triacontanol on growth and water relations in olive varieties under water stress. Indian J Plant Physiol 3:116-120.

[15] Ye QF, Zhou WJ, Xi HF, Fang JY (1995) Effect of S-3307 on levels of endogenous (IAA, ABA and ZT) and some physiological of rape seedlings. Acta Agri Zhejiang 7:451-456.

[16] Zhu LH, Peppal A, Li XY, Welander M (2004) Changes of leaf water potential and endogenous cytokinins in young apple trees treated with or without paclobutrazol under drought conditions. Sci Hort 99:133-141. 